\title{
Identidad y pacto social: los portugueses en Canarias durante la Unión Ibérica*
}

\section{Resumen}

Este trabajo aborda la conformación de una sociedad en áreas de frontera durante el periodo de consolidación de las relaciones atlánticas. A partir del examen de la documentación notarial y concejil insular se ha analizado como objeto de estudio a los portugueses que se establecen en Canarias y sus redes transfronterizas en el Océano con el objetivo de comprender el proceso de formación de una compleja identidad insular de origen exógeno en los límites de la Monarquía Hispánica y cuyo germen, concluimos, se encuentra en un pacto social entre locales y foráneos.

\section{Palabras clave}

Tesauro: identidad, isla, Océano Atlántico, Portugal, comunidad, historia moderna.

Referencia bibliográfica para citar este artículo: Álvarez Santos, Javier Luis. "Identidad y pacto social: los portugueses en Canarias durante la Unión Ibérica". Anuario de Historia Regional y de las Fronteras 24.1 (2019): 139-154.

Javier Luis Álvarez Santos: doctor en Historia por la Universidade Nova de Lisboa. Doctor en Historia por la Universidad de La Laguna. Diploma de Estudios Avanzados por la Universidad de La Laguna. Especialista Universitario en Archivística por la Universidad Nacional de Educación a Distancia. Licenciado en Historia por la Universidad de La Laguna. Profesor asociado de Historia de América en la Universidad de Las Palmas de Gran Canaria; miembro correspondiente del CHAM-Centro de Humanidades; miembro correspondiente del Instituto de Estudios Canarios; miembro correspondiente del Aula Canaria de Investigación Histórica; miembro del consejo editorial de la revista BACIH. Código ORCID: https://orcid. org/0000-0002-7845-6521. Correo electrónico: jlasantos@fcsh.unl.ptc.

\footnotetext{
${ }^{*}$ Este artículo surge como parte de la investigación desarrollada por el grupo de investigación Cultura, história e pensamento ibéricos e ibero-americanos del CHAM- Centro de Humanidades -FCSH/ NOVA-Uaç.
} 


\title{
Identity and Social Contract the Portuguese in the Canary Islands During the Iberian Union
}

\begin{abstract}
This research work addresses the formation of a society in frontier areas during the period of consolidation of Transatlantic relations. The Portuguese community established in the Canary Islands and their transboundary networks in the Ocean have been analysed from the study of notarial documentation and insular council in order to understand the process of formation of a complex and exogenous island identity within the limits of the Hispanic Monarchy, whose origin is found in a social contract between locals and foreigners.
\end{abstract}

Keywords

Thesaurus: Identity, Islands, Atlantic Ocean, Portugal, Communities, Modern history.

\section{Identidade e pacto social: os portugueses nas Ilhas Canárias durante a União Ibérica}

\section{Resumo}

Esta pesquisa trata da formação duma sociedade em áreas de fronteira durante o período de consolidação das relações atlânticas. A partir do estudo da documentação notarial e do conselho insular tem sido analisado como objeto de estudo os portugueses que se instalam nas Ilhas Canárias e suas redes transfronteiriças no Oceano com o objetivo de compreender o processo de formação de uma complexa identidade insular de origem exógena nos limites da Monarquia Hispânica e cuja origem, concluímos, está num pacto social entre os moradores locais e os estrangeiros.

\section{Palavras-chave}

Tesauro: identidade, ilha, Oceano Atlântico, Portugal, comunidade, história moderna. 


\section{Los orígenes del "pacto social"}

Señala Herzog que durante la Edad Moderna se distinguen dos modelos de comunidades: la comunidad local y la comunidad de súbditos. ${ }^{1}$ En el caso de Canarias la especificidad de local está condicionada por la geografía insular. El carácter fragmentado y aislado del territorio, al tiempo que fronterizo y relacionante del territorio, determina la naturaleza de sus habitantes y los diferencian de otras comunidades vasallas del monarca. Esta dualidad compuesta por las limitaciones geográficas y el dinamismo socioeconómico construye entre sus moradores -entre ellos los portugueses arraigados en las islas- una particular perspectiva del mundo insular y del entorno circunatlántico.

La explicitación en las fuentes primarias de la condición de vecino o estante revela mucho más que la estacionalidad del establecimiento nos remite a la relación del forastero con la nueva sociedad. Esta visibilidad revela el interés de estos foráneos por las Islas, ya fuese para su asentamiento o para abordar algún tipo de negocio. Asimismo, este incipiente nexo que se erige a partir del primer contacto condiciona la visión de la comunidad insular sobre estos individuos recién llegados. Por tanto, la expresión pública del origen exógeno, al igual que su estatus -vecino o estante- exhibe el carácter diferenciando del extraño frente al isleño. En definitiva, la exhibición de la naturaleza de un sujeto evoca el grado de implicación social. La palabra "nación", como precisa Cardim, era usada principalmente por quienes se encontraban fuera de su tierra. ${ }^{2}$ Este concepto estaba relacionado con una "conciencia colectiva" que refería a la pertenencia a una comunidad, fuera ésta conformada indistintamente por miembros oriundos de un mismo reino o no.

Por el contrario, la omisión de dicho origen implica la intencionalidad de ese sujeto por ser aceptado e integrado en la comunidad. La concesión del estatus jurídico ya fuese de natural o de vecino, especialmente en una sociedad periférica en constante transformación como la canaria, se legitimaba por el común de la sociedad silenciando su origen.

Siguiendo con los planteamientos de Herzog, durante el Antiguo Régimen la vecindad y la naturaleza llegaron a solaparse. El avecindamiento constituyó en sí mismo una forma de naturalización, permitiendo que los no nacionales se convirtiesen en naturales. Por consiguiente, el reconocimiento de la vecindad a un forastero por parte de la sociedad derivaba en la integración de éste como un miembro más de la comunidad. Por el contrario, no serlo, significaba recelo e, incluso rechazo. ${ }^{3}$

\footnotetext{
${ }^{1}$ Tamar Herzog, Vecinos y extranjeros. Hacerse español en la Edad Moderna (Madrid: Alianza Editorial, 2006) 30 .

${ }^{2}$ Pedro Cardim, "Los portugueses frente a la Monarquía Hispánica", La monarquía de las naciones: patria, nación y naturaleza en la monarquía de España, ed. Antonio Álvarez-Osorio Alvariño y Bernardo García García (Madrid: Fundación Carlos de Amberes, 2004) 376.

${ }^{3}$ Herzog 34.
} 
Junto a estas premisas de carácter general para la Monarquía Hispánica, las Islas presentaban ciertas especificidades acerca de la construcción de la imagen de la comunidad. Por un lado, el sustrato ibérico de la sociedad implicaba un apego a los valores nacionales que transmitía la Monarquía y el acatamiento generalizado del ordenamiento público del Reino. A este respecto, especialmente durante la Unión Ibérica, se difunde la noción de compartir un mismo horizonte hispánico por parte de las diversas comunidades vasallas del Rey Católico. Este carácter heterogéneo supranacional, casaba con la composición híbrida de la sociedad insular. En este microcosmos, la pluralidad de naciones -súbditas de un mismo monarca- no supuso más que la reafirmación en un ambiente local de un fundamento ideológico de la Monarquía.

Por otro lado, el condicionamiento geográfico y el carácter estratégico de las islas en el Atlántico igualmente promovió la arribada de multitud de gentes procedentes de otros lugares de Europa. El territorio insular, como tierra de naciones, determinó la formación de una identidad singular inserta en otra de mayor jerarquía.

De esta manera, este carácter insular de la población engarzado en los principios sobre los que se sustentaba la identidad hispánica definió la organización social en el ámbito local a partir de las aportaciones de diferentes componentes nacionales. La aceptación del individuo exógeno por parte de la sociedad vino dada por la consecución de su integración a través de diferentes estrategias desarrolladas a nivel insular.

En este espacio dinámico y relacionante, las cartas de naturalización supusieron más una excepción que la norma. Brito González, en su estudio sobre estos privilegios concedidos a extranjeros en Canarias, identificó únicamente 15 escrituras de este tipo para el período comprendido entre 1608 y 1773; esta cantidad irrisoria si se compara con las otorgadas para otros territorios castellanos. ${ }^{4}$ Igual de relevante es que ninguna de ellas fuera otorgada a portugueses. Asimismo, de esta quincena, solo tres se circunscriben al periodo de la Unión Ibérica - un par fueron dadas a individuos originarios de Flandes y una a un oriundo de Ruan-.

Por tanto, la admisión de un sujeto exógeno en la comunidad insular, ya de por sí de composición plurinacional en particular de los originarios de Portugal, está supeditada a la contribución de éste para dinamizar la Isla. El territorio insular, alejado de la metrópoli y de otras plazas relevantes del Atlántico, necesitaba de agentes ávidos de contactos que conectaran a estas ínsulas con el exterior y así asegurar el sustento de la sociedad. De este modo, durante el siglo XVI, y en especial a lo largo de la primera mitad del XVII, los comerciantes portugueses actuaron como nexo entre diferentes regiones atlánticas y el Archipiélago. El establecimiento de estos miembros de redes mercantiles era esencial para consolidar la presencia insular en los derroteros que enlazaban las distintas plazas de la Monarquía Hispánica en el océano.

\footnotetext{
${ }^{4}$ El mismo autor refiere el caso de Andalucía, donde se otorgaron 300 cartas de naturaleza. Alexis Brito González, "Naturalizaciones de extranjeros en Canarias en el Antiguo Régimen", XV Coloquio de Historia Canario-Americana (2002), coord. Francisco Morales Padrón (Las Palmas de Gran Canaria: Cabildo de Gran Canaria, 2004) 276.
} 


\section{La costumbre frente a la norma}

En 1561, la Monarquía había aumentado los requisitos necesarios para participar en el comercio indiano y, con ello, se les exigía a los extranjeros estar domiciliados en los territorios hispánicos durante más de diez años, con casa y bienes de asiento, y estar casados con mujer de la tierra. Fueron estas exigencias que se mantuvieron hasta 1608, momento en que se amplió el período de domiciliación a 20 años. $^{5}$

No obstante, estas medidas enfocadas a comprometer el vasallaje a un soberano y a consolidar el asentamiento de un individuo exógeno en el reino tampoco fueron aplicadas con rigurosidad en el territorio insular castellano. Estas disposiciones regias no supusieron un gran impedimento para el establecimiento y arraigo de individuos procedentes de comunidades foráneas, en especial la portuguesa, siempre y cuando fuesen aceptados éstos por la sociedad insular. La inclusión real y efectiva, por tanto, se garantizaba mediante un pacto entre el forastero y el común de la sociedad.

Hacia 1564, casi dos décadas antes de la agregación portuguesa a la Monarquía Hispánica, se instaló en la isla de Tenerife Pedro Afonso Mazuelos, un portugués natural de Guimarães. Poco sabemos de sus primeros años en la Isla. La documentación del Cabildo menciona por estas fechas varias veces a un individuo como "el portugués". 6 Por la cronología y las acciones que desarrolla-especialmente abasteciendo a la Isla, empleando para ello las redes mercantiles en las que está integrado, y en ocasiones concediendo créditos al Regimiento-, pensamos que se trata de la misma persona.

Es sintomático que a este individuo le denominen "el portugués". No se trata de una discriminación hacia él, como pudiera acontecer en otro contexto. Tampoco este apelativo incide en su condición de extranjero, a pesar de que nos referimos a una cronología anterior a la Unión Ibérica. Con el empleo del término "portugués", el Cabildo reafirma los vínculos tan relevantes que aporta este sujeto a la Isla.

Estas primeras aportaciones a la sociedad insular convirtieron a este individuo rápidamente en un miembro más de la comunidad local, confirmándose un pacto entre los insulares y el portugués. En 1575, la documentación notarial refiere ya a Pedro Afonso Mazuelos como vecino de Tenerife. ${ }^{7}$ Conocemos que, por estos años, poseía casa y diversas propiedades en la Isla. También sabemos que contrajo matrimonio en el territorio insular, aunque ignoramos cuándo fue realizado y si la cónyuge, Juana

\footnotetext{
${ }_{5}^{5}$ Ana Viña Brito, "Los flamencos en Canarias en el siglo XVI: ¿Una comunidad extranjera? Especificidades en la isla de La Palma”, Revista de Historia Canaria 194 (2012): 178.

${ }^{6}$ Como ejemplo, en 1576 el Cabildo compró a "el portugués" cierta cantidad de cal para las fortificaciones. Archivo Municipal de La Laguna, España (AMLL), Libros Capitulares, Oficio $1^{\circ}$, Libro 14, s.f.

${ }^{7}$ Probablemente con anterioridad ya hubiese sido referido como vecino, pero por las catas empleadas solo disponemos de registros notariales a partir de 1575 .
} 
Blanco, era natural de la Isla. ${ }^{8}$ Estas estrategias personales, conforme al derecho, así como en conformidad con los intereses locales, le permitieron mimetizarse rápidamente en la sociedad local. Este proceso de naturalización culminó en el mismo año de 1575, cuando juró como escribano público de Los Realejos por renuncia de Antón de Azoca. ${ }^{9}$

En menos de una década, este forastero se había convertido en un elemento relevante de la sociedad e, incluso, participó indirectamente a través de sus negocios en las decisiones del Regimiento. ${ }^{10} \mathrm{Su}$ capacidad de vincular a la Isla con el entorno portugués le convirtieron en un nexo indispensable entre los dos mundos. Véase como ejemplo elocuente que, en 1575, al llegar a Tenerife un poder desde Madeira de dos mercaderes franceses en lengua portuguesa, las autoridades locales pidieron a Pedro Afonso que lo tradujese. ${ }^{11}$

En un breve espacio de tiempo Mazuelos consiguió ser aceptado por la sociedad a través de los mecanismos legales, pero también empleando otros resortes que ayudaron a su naturalización, auspiciada por los miembros de la administración local. Así, en el año 1581 solicitaba este individuo el encabezamiento de las rentas del almojarifazgo, aunque sólo las logró obtener en 1585. Con esta aspiración por controlar las aduanas de la Isla, iniciaba Pedro Afonso Mazuelos una tradición, como sucediera en otras partes de Castilla, de intervención portuguesa en las rentas reales. Tras él, portugueses como Manuel de Oliveira, Luis Lorenzo, Tomás Pereira, etc., hasta la marcha de Duarte Enríquez en 1652, controlaron el fisco y las aduanas de Tenerife, la isla con más población y con mayor proyección internacional. Esta supervisión, de las mercancías que entraban y salían, en un territorio tan dinámico como este, otorgaba a estos individuos cierto poder local.

También este interés por el control aduanero estaba estrechamente vinculado al entorno circunatlántico en el que está encajado el Archipiélago. La dependencia del territorio insular de los circuitos mercantiles lusos condicionaba cierto interés por parte de la oligarquía para favorecer la presencia de alguien de confianza y miembro de la vasta red portuguesa para supervisar la actividad mercantil en los puertos insulares.

\footnotetext{
${ }^{8}$ Tal vez esta Juana Blanco, fuera pariente del mercader flamenco Pedro Blanco, con quien mantuvo intenso trato Pedro Afonso Mazuelos.

${ }^{9}$ Archivo Municipal de La Laguna, España (AMLL), Libros Capitulares, Oficio $2^{\circ}$, Libro 2, fo 427v. Cargo en el que es ratificado un año después y que ocupó hasta 1578. Archivo Municipal de La Laguna, España (AMLL), T-XIX, 20.

${ }^{10}$ Durante la década de los 80 del siglo XVI el Regimiento acude a Pedro Afonso Mazuelos en una decena de ocasiones para que le preste dinero para poder hacer frente a ciertas deudas que mantiene la citada institución. Otras veces, se le solicita que intervenga directamente en el abastecimiento de la Isla, por ejemplo para traer 1.000 fanegas de trigo compradas al vicario de la isla de Gran Canaria. Archivo Municipal de La Laguna, España (AMLL), Libros Capitulares, Oficio 2 ${ }^{\circ}$, Libro 4, f 110.

${ }^{11}$ En esta misiva se pedía que se cobrase a un comerciante flamenco todas las mercancías que le pertenecían. Archivo Histórico Provincial de Santa Cruz de Tenerife, España, (AHPSCT), Sección Histórica de Protocolos Notariales, leg. 1002, fo 374v.
} 
Sin embargo, esta red a la que pertenece Pedro Afonso Mazuelos -al igual que ocurre con otros portugueses- no estaba constituida exclusivamente por agentes coterráneos. Se trataba de una red transnacional. Por un lado, participaba este individuo directamente en negocios con Portugal, otorgando letras a Lisboa y Oporto, así como remitiendo vinos canarios a Brasil o tratando con comerciantes de esclavos africanos asentados en Canarias. Por otro, actuaban conjuntamente en esta red individuos de otras naciones; así fletaba Pedro Afonso en compañía del flamenco Pedro Huesterlin, también vecino de Tenerife, un navío para llevar a Bahía 12 pipas de vino en nombre de Juan Cosquer, vecino de Lisboa. ${ }^{12}$ Como indica Sullón Barreto para el caso de Lima, los portugueses allí establecidos no constituyeron un grupo endogámico dentro del conjunto de la sociedad, al igual que en Canarias, desarrollaron relaciones afectivas, económicas y sociales con otros miembros de la comunidad. ${ }^{13}$

De esta manera, el lazo entre naciones va más allá del vínculo mercantil. En una sociedad de frontera, de composición social mixta y donde el contingente exógeno es fundamental para dar cohesión entre lo interno y lo externo, obligaba a todos los grupos sociales a aunar lazos y estrategias. Pedro Afonso Mazuelos, en su testamento, ordenó traer a la Isla un retablo procedente de Flandes. Para ello comprometió, además de a sus dos albaceas, a Pascual Leardín, otro importante comerciante flamenco con el que había realizado numerosos negocios. ${ }^{14}$

Estas relaciones en las que se inserta Pedro Afonso se mantuvieron en su ausencia, demostrando la solvencia de la red portuguesa en que actuaba. Años después de su fallecimiento, su hija contraerá matrimonio con otro portugués arraigado en la Isla. ${ }^{15}$ En este caso, ni la naturalización ni la mimetización social es necesaria, pero sí es determinante reavivar los contactos que dan sentido a la identidad de esta comunidad.

Las actividades en las que participa Pedro Afonso Mazuelos dan muestra de la pluralidad de naciones existentes en Canarias, así como de la coexistencia y relaciones entre ellas para conectar al territorio insular con el exterior. Por tanto, estamos definiendo la composición de la sociedad insular como plural y diversificada, donde la naturalización se podía llegar a conseguir a cambio de un aporte a la comunidad. Desde esta perspectiva, no podemos categorizar a Pedro Afonso Mazuelos, así como a otros oriundos de Portugal, exclusivamente como portugueses, ya que así no lo entendía la sociedad del momento. Es portugués al mismo tiempo que insular, por su

\footnotetext{
${ }^{12}$ Archivo Histórico Provincial de Santa Cruz de Tenerife, España, (AHPSCT), Sección Histórica de Protocolos Notariales, leg. 1055, f 322.

${ }^{13}$ Gleydi Sullón Barreto, "Relaciones de los portugueses en Lima con otros grupos étnicos, 1570-1680", América en la Memoria: Conmemoraciones y Reencuentros, t. II. (Bilbao: Asociación Española de Americanistas, 2013) 546.

${ }^{14}$ Constanza Negrín Delgado, "Las mandas piadosas del portugués Pedro Afonso Mazuelos. Su institución y cumplimiento en la iglesia parroquial de Nuestra Señora de los Remedios, a través de las escribanías de La Laguna", Anuario del Instituto de Estudios Canarios 41 (1996): 271-324.

${ }_{15}$ Archivo Histórico Provincial de Santa Cruz de Tenerife, España, (AHPSCT), Sección Histórica de Protocolos Notariales, leg. 1532, f $274 \mathrm{v}$.
} 
contribución a la comunidad como nexo entre el ámbito local y el entorno atlántico. En consecuencia, la diversidad de naciones y de redes establecidas en el Archipiélago, siempre respaldadas por la oligarquía local, garantizaba al conjunto mantener el trato dependiente con el exterior. De esta manera, la extranjería no era un impedimento para la naturalización, sino una condición que llegaba a favorecer la integración en un territorio alejado y necesario de vínculos.

\section{Lazos internacionales y compromiso local como vías para la naturalización}

Más allá de la legislación y de las vías jurídicas que concedían la naturalización, se priorizaba la aportación del sujeto a la sociedad. El establecimiento de un agente portugués en el Archipiélago aseguraba el abastecimiento, consolidaba rutas mercantiles y abría la posibilidad de conectar con nuevos consumidores. Por consiguiente, de esta contribución a la sociedad dependía la rapidez con la que era agregado a la misma.

Los extensos y sólidos lazos mercantiles que aportan los forasteros, en especial los portugueses, al dinamismo económico de Canarias cuando se asientan y su disposición a colaborar con los interlocutores locales determinaron las vías de su integración. Aunque no hemos localizado ningún documento anterior a 1617, el Nobiliario refiere que el portugués Tomás Pereira habría llegado a Tenerife en 1610 o 1611 para administrar los bienes del Adelantamiento de Canarias, cuya titular era la Princesa de Ásculi. ${ }^{16}$ Justamente a comienzos de 1617 se refiere la documentación notarial a este individuo como "estante".

No parece que tuviese un proceso de integración fácil, ya que en ese año era acusado de haberse llevado la virginidad de una moza. Aunque posteriormente la denunciante se desdijo aduciendo haber estado mal aconsejada, ${ }^{17}$ se desprende de este hecho que este individuo, que llegó a ostentar el cargo de regidor, en esta época inicial de su estancia en la Isla aún no había consolidado sus lazos con la sociedad. Transmite todavía cierta desconfianza hacia los insulares. No había sido aceptado por la comunidad y no dispone de los privilegios de los naturales ni el respaldo de un sector de la élite social. Aun sus acciones en la Isla no habían repercutido claramente en el beneficio de los insulares.

Por las actividades en las que participa en esta época observamos que se trata de un simple agente luso casi exclusivamente ligado a los intereses de las redes mercantiles portuguesas. Actuó como fiador de un navío portugués cargado de pipas y esclavos africanos para el Brasil, ${ }^{18}$ introdujo mercancías de Portugal $^{19}$ y

\footnotetext{
${ }^{16}$ Francisco Fernández de Béthencourt, Nobiliario de Canarias (La Laguna: J. Régulo Ed., 2004) 276.

${ }^{17}$ Archivo Histórico Provincial de Santa Cruz de Tenerife, España, (AHPSCT) Sección Histórica de Protocolos Notariales, leg.1534, fo 432.

${ }_{18}$ Archivo Histórico Provincial de Santa Cruz de Tenerife, España, (AHPSCT), Sección Histórica de Protocolos Notariales, leg.1534, fo 194.

${ }^{19}$ Archivo Histórico Provincial de Santa Cruz de Tenerife, España, (AHPSCT), Sección Histórica de
} 
otorgó créditos a cobrar en Lisboa a nombre de su cuñado, Payo Rodríguez de Paz. ${ }^{20}$ Se desprende que en esta etapa inicial los lazos familiares son fundamentales para consolidar esta red. Así, un año más tarde otorgó un poder a su hermano, Domingos Pereira, residente en la Corte, para que en su nombre actuase ante los Consejos, "así de Indias como otros". ${ }^{21}$

Este año de 1618 fue crucial para por fin consolidar la integración de Tomás Pereira en la sociedad insular al tiempo que se afianzó como agente participe de una importante red mercantil. A comienzos de ese año contrajo matrimonio con Bárbara Carrasco de Ayala y Ocampo, hija del capitán Juan Carrasco de Ayala y Llarena, regidor perpetuo de la Isla. ${ }^{22}$ Además, por esa misma época se estableció también en Tenerife su hermano, Diego Pereira de Castro.

A partir de este momento, Tomás Pereira compaginó los negocios de la red internacional con los intereses económicos de la Isla, o por lo menos de parte de su oligarquía. Desde Canarias continuó tratando con sus familiares residentes en la Corte -Simón Pereira, Payo Rodríguez de Paz y Domingos Pereira- para que pudiesen asegurar el encabezamiento de las rentas reales para el año $1620 .{ }^{23} \mathrm{Al}$ mismo tiempo, enlazó en esta red internacional con los miembros de la élite local, haciendo partícipe en sus negocios de exportación de vinos a Brasil en forma de compañía a su yerno, Juan Carrasco. ${ }^{24}$

Las actividades mercantiles que llevó a cabo se vuelven cada vez más complejas. Comerció con la América española y con África e, incluso, a veces hizo de nexo entre estos dos territorios. En 1618 vendió a un maestre de navío que se dirigía a Nueva España cuatro esclavos negros. Pero se trataba de una falsa transacción. Aunque la sociedad insular ya lo había aceptado como "vecino", no estaba aún reconocido como natural de la Isla en otros territorios de Castilla. En ocasiones, se vio obligado a emplear ciertas argucias para poder comerciar con las Indias. En este caso, aunque la venta oficial de los esclavos había sido realizada a un navegante vecino del puerto de Santa Cruz, el riesgo, pero también los beneficios de la trata de los esclavos en América iban registrados a su nombre en la primera flota de la Carrera de Indias que regresase a Castilla. ${ }^{25}$

Protocolos Notariales, leg.1534, f $\mathrm{f}^{\mathrm{2}} 255 \mathrm{v}$.

${ }^{20}$ Archivo Histórico Provincial de Santa Cruz de Tenerife, España, (AHPSCT), Sección Histórica de Protocolos Notariales, leg.1534, fo 292.

${ }^{21}$ Archivo Histórico Provincial de Santa Cruz de Tenerife, España, (AHPSCT), Sección Histórica de Protocolos Notariales, leg.1536, fo 278.

${ }^{22}$ Fernández de Béthencourt 277.

${ }^{23}$ Archivo Histórico Provincial de Santa Cruz de Tenerife, España, (AHPSCT), Sección Histórica de Protocolos Notariales, leg.1538, fo 535.

${ }^{24}$ Archivo Histórico Provincial de Santa Cruz de Tenerife, España, (AHPSCT), Sección Histórica de Protocolos Notariales, leg.1538, f 311.

${ }^{25}$ Archivo Histórico Provincial de Santa Cruz de Tenerife, España, (AHPSCT), Sección Histórica de Protocolos Notariales, leg.1536, fo 345. 
En otra ocasión, con la misma intención de comerciar sin impedimentos con América, traspasó una nao a un vecino de Garachico por 30.000 reales. Seguidamente, en el mismo día, este nuevo dueño de la embarcación, la fletaba al propio Tomás Pereira para cargar 300 pipas de vino a Pernambuco por valor de 14.250 reales. Asimismo, lo procedido de la venta de los caldos, los debía emplear el mareante en comprar azúcar para llevarlo a Portugal, pagando por tonelada 250 reales. Todo este negocio montaba unos 38.000 reales, cantidad sustancialmente superior al negocio inicial por el navío. ${ }^{26}$

Además, en estas dispares artimañas empleadas por Pereira estaban involucrados otros miembros de la comunidad insular. En 1617, un navío portugués que se dirigía a Azores, con destino a Pernambuco, por culpa de vientos contrarios recaló en Tenerife. La embarcación portaba más de un centenar de pipas vacías, además de 20 cueros de buey, cuatro cajas azúcar de blanco y diez esclavos. Al llegar a puerto, las autoridades le pidieron pagar los derechos y que hiciese las correspondientes fianzas. Estas mercancías estaban registradas a nombre de Domingos Gil de Fonseca, vecino de Oporto, por lo que el maestre necesitó de un fiador. Tomás Pereira, a ruego del dicho mareante, salió como garante. Esta historia se revela como ficticia cuando descubrimos, en una escritura notarial del mismo día de la fianza, que dicho maestre tenía crédito y orden del citado Domingos Gil para que Tomás Pereira de Castro cargase a su cuenta 60 pipas de vino para llevar a Pernambuco. ${ }^{27}$

Estas estrategias demuestran, por un lado, la importancia para la economía insular de las redes mercantiles en las que participan los portugueses. Por otro, la colaboración de la sociedad insular en estas tretas. Estos agentes lusos son el nexo entre el sistema atlántico y el Archipiélago. Los intereses de los insulares y de estos forasteros se solapan, pero no se producen disputas durante este período, sino que se articulan mecanismos que facilitan la colaboración. Por tanto, la cooperación en estos negocios internacionales de castellanos insulares y portugueses otorgaban a estos últimos la confianza necesaria para ser aceptados e integrados en la sociedad insular.

En otros ambientes de la sociedad insular también se detecta cómo la nacionalidad es una frontera fácilmente permeable. El origen no debió condicionar la integración del individuo exógeno con la comunidad, sino que es la relación que mantiene con la ínsula y el exterior lo que determina el tipo de vínculos que crea con los insulares. En 1626, Antonio de Morales, vecino de Braga, se presentó ante el teniente general de la isla de Tenerife con una información que atestiguaba que era padre de Gregorio de Morales, menor de veinticinco años, vecino de Tenerife y casado en dicha Isla. El progenitor se había trasladado desde el reino de Portugal hasta la Isla

\footnotetext{
${ }^{26}$ Archivo Histórico Provincial de Santa Cruz de Tenerife, España, (AHPSCT), Sección Histórica de Protocolos Notariales, leg.1538, fo 1006 y Archivo Histórico Provincial de Santa Cruz de Tenerife, España, (AHPSCT), Sección Histórica de Protocolos Notariales, leg.1538, fo 1008.

${ }^{27}$ Archivo Histórico Provincial de Santa Cruz de Tenerife, España, (AHPSCT), Sección Histórica de Protocolos Notariales, leg.1534, f 194 y Archivo Histórico Provincial de Santa Cruz de Tenerife, España, (AHPSCT), Sección Histórica de Protocolos Notariales, leg.1534, fo 195v.
} 
para solicitar una limosna a su vástago porque estaba viviendo en mucha pobreza. ${ }^{28}$ Enterado de ello, su hijo le dispensó 2.000 reales.

En este ejemplo no podemos discernir si existe una delimitación clara entre la condición de portugués o insular de Gregorio de Morales. ¿Pertenece a la comunidad portuguesa o a la canaria? ¿Es un luso avecindado en la Isla o un insular nacido en Portugal? Su ascendencia es lusa, además ha mantenido algún contacto con su familia. Sin embargo, se encuentra arraigado en la Isla, donde ha constituido una nueva familia. En nuestra opinión, aunque aventuramos su naturaleza, es imposible distinguir su nación o grupo al que pertenece dentro de la sociedad insular porque el origen luso es a su vez un elemento constitutivo de la comunidad de la Isla. Cierto es que ser natural de Portugal no es sinónimo a ser castellano, pero un portugués integrado puede identificarse como un miembro de la sociedad y, en consecuencia, como isleño.

Entonces, ¿qué es ser portugués en Canarias durante los años de la Unión Ibérica? ¿La condición de no castellano restringió las relaciones entre la sociedad insular y los portugueses que llegaron a las islas? ¿Existió una frontera que limitase la comunicación y el trato entre individuos del Archipiélago y del entono portugués? Creemos que, en el fondo, mediante una simbiosis entre comunidades, se produjo una transferencia del bagaje portugués a la identidad insular, teniendo ésta un carácter tradicionalmente acumulativo.

Si bien el avecindamiento era la primera vía para lograr la integración, éste no parece ser la única condición que permitía conseguir cierta estabilidad y arraigo en las sociedades insulares del Antiguo Régimen. De esta manera, que un individuo fuese "vecino" de Portugal no le excluía de actuar dentro de la comunidad insular ni de conformar ciertos vínculos con ésta, incluso de carácter parental. Por un lado, la condición de vecino de un territorio tan próximo, con tanto trato social y económico, expresaba no sólo la procedencia, sino que aludía también a los contactos y al tipo de bagaje cultural que introducía en la sociedad. Por otro lado, las similitudes culturales y lingüísticas favorecieron el proceso de mimetismo social. ${ }^{29}$

\footnotetext{
${ }^{28}$ Archivo Histórico Provincial de Santa Cruz de Tenerife, España, (AHPSCT), Sección Histórica de Protocolos Notariales, leg.2104, s. f.

${ }^{29}$ Apunta Herzog como hipótesis en el análisis del estatuto jurídico de los moradores de la América portuguesa que "não existiam "vizinhos", mas sim "nobres da terra", não existindo tão-pouco naturais que pudessem ser diferenciados dos vassalos". Continua la investigadora afirmando que este grupo de los "Nobres da terra" podia incluir-e frequentemente tal acabou por acontecer-pessoas de diferentes profissões e de variado estatuto económico, social ou cultural, podendo até abarcar, em certas ocasiões, pessoas descendentes de uniões mistas. [...] Declarar que uma pessoa era "da terra" constituía, por conseguinte, a maneira mais rápida de estabelecer a sua identificação com a localidade, uma assimilação que conferia uma série de direitos, no topo dos quais estava a prioridade - ou até mesmo o completo monopólio -no acesso aos ofícios, incluindo benefícios eclesiásticos. E ainda que, por vezes, a distinção "da terra" fosse identificada com nascimento ou com descendência, na maioria dos casos dependia de outros factores, com destaque para a residência prolongada". Tamar Herzog, "A história ibérica recontada? Vecindad e Naturaleza em Castela, em Portugal e nos seus domínios ultramarinos durante o século XVII", Repensar a identidade. O mundo ibérico nas margens da crise da consciência europeia, org. David Martín Marcos y otros (Lisboa: Centro de História d'Aquém e d'Além Mar, 2015) 304 y 307.
} 
La nacionalidad de estos portugueses que se establecieron en Canarias no era un elemento que condicionase la integración en la sociedad. Si en cierta documentación analizada - como fletes, contratos de compraventa, poderes, letras, etc.- se mencionaba la naturaleza o la procedencia lusa era porque en la percepción del común de los isleños sobre esta categoría los distinguía del resto de la sociedad, ya fuese por sus contactos - participando en circuitos internacionales mercantiles o actuando en pequeñas redes parentales o gremiales- o por sus cualidades para el desempeño de determinados oficios, por ejemplo en las labores especializadas de la caña de azúcar o en algunos trabajos artesanales.

Al fin y al cabo, son los isleños quienes evaluaban y aceptaban en su comunidad a los forasteros. En definitiva, para que fuesen aceptados estos no castellanos -y en particular sobre los portugueses- la sociedad insular debía conocer, además del lugar de procedencia, con quiénes se relacionaban -dentro y fuera de la Isla-, a qué redes pertenecían, qué contactos mantenían y, sobre todo, qué podían aportar al colectivo social.

Esta integración social conllevaba que la comunidad depositase la confianza en el individuo. Como miembro del grupo, el portugués arraigado, estaba obligado a cumplir con su deber con la sociedad. Así, no es de extrañar que al mercader Manuel Díaz, de origen portugués pero asentado en Tenerife, el padre de huérfanos nombrado por el Regimiento pusiese bajo la tutela de éste a un niño de diez años cuyos padres eran naturales de la Isla. ${ }^{30}$ En este caso, la autoridad local no acudió a un castellano para que "castellanizase" al mozo, sino a un individuo - natural de Portugal-arraigado en la sociedad para que el joven pudiera ser partícipe de esa misma integración.

Las decisiones sobre con quién se puede negociar topan con las imposiciones de la metrópoli y su percepción de la ecúmene con las necesidades e intereses de una comunidad en un contexto insular. A la administración mediata de las islas le importaba mantener activo el trato con los vecinos portugueses, sea este lícito o no. Además, la sociedad acogía a estos agentes que se establecían en las islas, ya que aportaban capital, fuerza de trabajo y, sobre todo contactos con el exterior.

De esta manera, las relaciones con Azores y Madeira fueron fundamentales para consolidar el bienestar insular mediante la complementariedad. Igualmente, Portugal y, fundamentalmente Angola y Brasil, se convirtieron en los principales mercados de exportación del vino canario. También portugueses y canarios actuaron directamente en el resgate de esclavos a los Ríos de Guinea, aunque esto supusiera contravenir la legalidad y quebrar la exclusividad del comercio esclavista que ostentaba Cabo Verde. ${ }^{31}$ Como compensación, este trato directo con el entorno

\footnotetext{
${ }_{30}$ Archivo Histórico Provincial de Santa Cruz de Tenerife, España, (AHPSCT), Sección Histórica de Protocolos Notariales, leg.1532, $\mathrm{f}^{\mathrm{0}} 74 \mathrm{v}$.

${ }^{31}$ A pesar de las continuas quejas de los moradores de Santiago al Monarca y de las disposiciones regias que, como la de 1609, obligaban a los navíos de Castilla y Canarias que iban a Guinea, ir primero a despachar a Cabo Verde, la dinámica interna del circuito sobrepasaba los procedimientos legales para su fiscalización. Tanto los mareantes como los comerciantes establecidos en Guinea, así como los agentes en
} 
portugués suponía también la entrada constante de mercancías y personas lusas. Por tanto, el bagaje portugués a la conformación social tinerfeña es sustancialmente relevante, tanto por el número de individuos que se integraron como por la fluidez en el trato entre ambos espacios atlánticos.

\section{La Restauración y el final del "pacto social"}

En cambio, si este pacto social se trunca -como sucedió tras la sublevación portuguesa- la comunidad que les había acogido se vuelve recelosa. Las acciones de este grupo ya no benefician al conjunto de la sociedad, sino a ellos mismos. Las redes mercantiles que habían atraído estos individuos a las islas y en las que participaban la élite insular, se alejaban del Archipiélago. Además, los escasos negocios que permanecieron tras el cambio de coyuntura en el Atlántico pasaron a estar controlados por agentes e intereses externos, independientes de los órganos de poder locales. En consecuencia, aquellos que se habían insularizado pero que mantenían algún vínculo con los rebeldes, pasaron entonces a formar parte de un grupo exógeno.

La Restauración portuguesa construyó una nueva frontera social que hasta entonces no había existido en las islas de la Macaronesia. Sobre esta entidad, los insulares, cernieron la desconfianza y el rechazo. ${ }^{32}$ En el ambiente se denotaba cierto temor por los acontecimientos que se sucedían fuera del Archipiélago. Las informaciones que llegaban al Cabildo de Tenerife hablaban de una invasión plausible desde la vecina Madeira. De este modo, el enemigo comenzaba a construirse a partir de hechos exógenos y no por tensiones internas. El caos incipiente fue aprovechado por algunos miembros de la comunidad para levantar acusaciones en beneficio propio, como ya hemos ejemplificado en el caso de Lanzarote. La línea que separaba a canarios de los portugueses arraigados era confusa. Al fin y al cabo, todos eran isleños, participes de un mismo universo.

Los principales hombres de Tenerife, entre ellos varios portugueses arraigados en la isla desde hacía muchos años, se lamentaban por las trágicas consecuencias de la emancipación de Portugal y sus territorios de ultramar. ${ }^{33}$ Con la pérdida de los mercados

\footnotetext{
Canarias, preferían un trato directo que eludiesen a las autoridades. Maria Manuel Ferraz Torrão, "Rotas comerciais, agentes económicos, meios de pagamento", História geral de Cabo Verde, t. II., coord. Maria Emília Madeira Santos (Lisboa: Instituto de Investigação Científica Tropical, 1995) 113.

${ }^{32}$ Con las primeras noticias de la sublevación portuguesa, “[...] La justicia y regimiento dijeron que este negocio es el más grave y de importancia que puede haber en estas islas porque con el levantamiento de Portugal, no solo queda cerrada la puerta a todo trato, sino a que carezca esta república de todo lo necesario". Archivo Municipal de La Laguna, España (AMLL), Libros Capitulares, Oficio $2^{\circ}$, Libro $13, \mathrm{f}^{\mathrm{o}} 213$.

${ }^{33}$ Cristóbal Salazar de Frías, un acomodado portugués que se había establecido en Tenerife a principios de siglo, se lamentaba, aún varios años después del levantamiento, de esta situación ante sus colegas del Cabildo. Decía en 1645 que "[...] es muy público y notorio la gran quiebra y miseria en que esta isla y las demás han venido con la guerra, así del levantamiento de Portugal, con quien tenían gran comercio como de las partes del Brasil que los holandeses han ocupado. Y ha llegado esto a tan miserable estado que si no se procura con mucha brevedad y grandes [ilegible] el remedio de este daño se perderán estas islas y se despoblarán, porque el punto principal de que se valen y sustentan son las viñas [...]”. Archivo Municipal de La Laguna, España (AMLL), Libros Capitulares, Oficio 2º, Libro 14, fo 218.
} 
portugueses, la ínsula desaparecía temporalmente del mapa mercantil del Atlántico portugués. Los vínculos se habían quebrado y con ello la participación de Canarias en las relaciones oceánicas con el entorno luso. Además, el comercio transatlántico que hasta entonces estaba principalmente en manos de hispánicos, pasó a estar intervenido por otras naciones, copando rutas y mercados. A partir de la ocupación holandesa de Brasil y el intervencionismo mercantilista inglés, el Atlántico dejó de ser para los súbditos ibéricos un Mare Clausum con el que habían soñado desde las primeras exploraciones oceánicas para convertirse definitivamente en un Mare Liberum.

En estos años que se suceden a la Restauración, Inglaterra se convirtió en una de las principales potencias marítimas y comerciales, reemplazando el dominio luso-castellano en el Atlántico. Este nuevo dominio se volvió efectivo con las Actas y Leyes de Navegación inglesas, de mediados del Seiscientos. Estas disposiciones liberalizaban las importaciones de vino, especialmente de los caldos portugueses, los cuales comenzaron a sustituir la oferta canaria en el mercado inglés. Más concretamente, las Actas de Navegación (1663) prohibieron el comercio directo de los vinos del Archipiélago a las colonias inglesas, favoreciendo las exportaciones madeirenses. Además, la fortaleza de la autoridad británica sobre las Islas se acrecentó con la constitución de la Compañía de Canarias en 1665, quedando todo el comercio entre Inglaterra y el Archipiélago en manos de estos extranjeros.

La tensión surgida de los acontecimientos y el recelo sobre la comunidad de portugueses que se mantiene en Canarias trajo como consecuencia la construcción en el imaginario local de una nueva alteridad. La cultura-nación portuguesa ya no es un componente de la sociedad insular, sino un grupo diferenciado. Este desapego y desconfianza se llegó a materializar en momentos de tensión y conflicto, achacando los isleños a la comunidad portuguesa ciertos males que sufría el Archipiélago.

En 1648, Francisco de Franchy y Alfaro, un ilustre miembro de la oligarquía de Tenerife, escribió un memorial al rey para explicarle las penurias y agravios que estaba sufriendo esta localidad. El objetivo de esta misiva no era otro que conseguir para esta población de La Orotava el título de villa exenta y así liberarse la élite local del control del Cabildo lagunero. Entre los argumentos que presentaba al Monarca exponía que numerosos portugueses hacían y deshacían a sus anchas en el puerto de este lugar. Cita a un clan familiar de origen portugués constituido por cuatro individuos, todos ellos toneleros, a cuya cabeza estaba Nicolás Álvarez. Éste trataba ilícitamente con el comercio americano, en ocasiones, a través de navíos enemigos como lo eran los holandeses. También era cómplice de apoyar a otros coterráneos suyos rebeldes que trataban con la América española. Incluso había acogido en su propia casa a varios portugueses que habían venido de Buenos Aires y se dirigían a Lisboa con la plata americana. Asimismo, también le acusaba de haber vendido una fragata a los ingleses para ser despachada a Angola o a los Ríos de Guinea.

Estos no son los únicos portugueses en La Orotava, Franchy y Alfaro refiere que hay "treinta o cuarenta vecinos de nación portugueses", de los cuales el autor del memorial recela afirmando que "[...] en su población no ay persona de calidad de quien esto pueda fiarse". No obstante, no es una desconfianza únicamente hacia 
los lusos, sino a todos aquellos forasteros que no se integraban y aportaban algún beneficio a la sociedad local,

[...] compuestose parte de su vecindad de diferentes naciones de portugueses, yngleses, catalanes, y françeses y otras personas que de diversas poblaciones an benido a avecindarse en el dicho puerto que no tienen ni se les conoce vienes raices ningunos y que solo viven de embarcar, traxinar, y rebatir las mercaderías. ${ }^{34}$

Este acontecimiento revelaba por primera vez la existencia un pensamiento generalizado de la sociedad isleña sobre este colectivo. La comunidad portuguesa afloraba como entidad en el ámbito del cambio de coyuntura socioeconómica de la Isla. El vino, el principal producto exportador y sobre el que se había sustentado el modo de vida insular, se encontraba en decadencia en la década de los 40. Años antes, se había perdido el principal mercado al que se vendía los caldos y desde Sevilla se presionaba para que se subieran los aranceles al comercio americano e, incluso, se le llegó a prohibir a Canarias tratar con Indias.

Por otro lado, en este nuevo contexto insular, el negocio del vino se encontraba en manos de mercaderes extranjeros, interesados en revertir el lucro del comercio en la red a la que pertenecía su comunidad en lugar de invertir en el ámbito local. Concretamente, el grupo de portugueses mudó de intenciones en el Archipiélago, así como de estrategia con los insulares y de aliados. El trato tradicional se había roto y la complementariedad dio paso a la competencia. El portugués, por tanto, pasó a ser considerado como un elemento exógeno cuya identidad se encontraba desde entonces bien perfilada y distinguida de la insular.

Esta nueva coyuntura, propiciada por acontecimientos extrainsulares, predispuso a los insulares a definir al individuo portugués bajo parámetros que se contraponían a los empleados hasta el final de la Unión Ibérica, por cuanto la conciencia insular no había identificado a la comunidad portuguesa como un componente segregado de la composición de su identidad. La Restauración portuguesa y el cambio de dominio en el Atlántico germinaron una dicotomía inexistente hasta entonces en la cosmovisión del insular, delimitándose una frontera física y afectiva entre las islas y los isleños con el entorno portugués.

\section{Bibliografía}

\section{Fuentes primarias}

\section{Fuentes de archivo}

Archivo Histórico Provincial de Santa Cruz de Tenerife, España, (AHPSCT), Archivo Zárate- Cologan.

Archivo Histórico Provincial de Santa Cruz de Tenerife, España, (AHPSCT), Sección Histórica de Protocolos Notariales

${ }^{34}$ Archivo Histórico Provincial de Santa Cruz de Tenerife, España, (AHPSCT), Archivo Zárate- Cologan, Sig. 1020, f 714 . 
Identidad y pacto social: los portugueses en Canarias durante la Unión Ibérica

Archivo Municipal de La Laguna, España (AMLL), Libros Capitulares.

Archivo Municipal de La Laguna, España (AMLL), T-XIX.

\section{Fuentes secundarias}

\section{Libros}

Fernández de Béthencourt, Francisco. Nobiliario de Canarias. La Laguna: J. Régulo Ed., 2004.

Herzog, Tamar. Vecinos y extranjeros. Hacerse español en la Edad Moderna. Madrid: Alianza Editorial, 2006.

\section{Capítulos de libros}

Brito González, Alexis. "Naturalizaciones de extranjeros en Canarias en el Antiguo Régimen", XV Coloquio de Historia Canario-Americana (2002). Coord. Francisco Morales Padrón. Las Palmas de Gran Canaria: Cabildo de Gran Canaria, 2004.

Cardim, Pedro. "Los portugueses frente a la Monarquía Hispánica", La monarquía de las naciones: patria, nación y naturaleza en la monarquía de España. Ed. Antonio Álvarez-Osorio Alvariño y Bernardo García García. Madrid: Fundación Carlos de Amberes, 2004.

Herzog, Tamar. "A história ibérica recontada? Vecindad e Naturaleza em Castela, em Portugal e nos seus domínios ultramarinos durante o século XVII", Repensar a identidade. O mundo ibérico nas margens da crise da consciência europeia. Org. David Martín Marcos, José María Iñurritegui y Pedro Cardim. Lisboa: Centro de História d'Aquém e d'Além Mar, 2015.

Sullón Barreto, Gleydi. "Relaciones de los portugueses en Lima con otros grupos étnicos, 1570-1680", América en la Memoria: Conmemoraciones y Reencuentros, t. II. Bilbao: Asociación Española de Americanistas, 2013.

Torrão, Maria Manuel Ferraz. "Rotas comerciais, agentes económicos, meios de pagamento", História geral de Cabo Verde, t. II. Coord. Maria Emília Madeira Santos. Lisboa: Instituto de Investigação Científica Tropical, 1995.

\section{Artículos de revista}

Negrín Delgado, Constanza. "Las mandas piadosas del portugués Pedro Afonso Mazuelos. Su institución y cumplimiento en la iglesia parroquial de Nuestra Señora de los Remedios, a través de las escribanías de La Laguna", Anuario del Instituto de Estudios Canarios 41 (1996): 271-324.

Viña Brito, Ana. "Los flamencos en Canarias en el siglo XVI: ¿Una comunidad extranjera? Especificidades en la isla de La Palma", Revista de Historia Canaria. 194 (2012): 161-192. 